\title{
Mechanical stability investigation of advanced composite plates resting on elastic foundations using a new four-unknown refined theory
}

\author{
Yassine Khalfi \\ Université de Sidi Bel Abbes, BP 89 Cité Ben M'bidi 22000 Sidi Bel Abbes, Algérie \\ khalfiyassinesba@yahoo.fr
}

\author{
Aboubakar Seddik Bouchikhi, Yassine Bellebna \\ Université de Sidi Bel Abbes, Ecole National Polytechnique D'oran \\ asbouchiki@yahoo.fr,yassinebellebna@yahoo.fr
}

\begin{abstract}
A refined and simple shear deformation theory for mechanical buckling of composite plate resting on two-parameter Pasternak's foundations is developed. The displacement field is chosen based on assumptions that the in-plane and transverse displacements consist of bending and shear components, and the shear components of in-plane displacements give rise to the parabolic variation of shear strain through the thickness in such a way that shear stresses vanish on the plate surfaces. Therefore, there is no need to use shear correction factor. The number of independent unknowns of present theory is four, as against five in other shear deformation theories.It is assumed that the warping of the cross sections generated by transverse shear is presented by a hyperbolic function. The stability equations are determined using the present theory and based on the existence of material symmetry with respect to the median plane.The nonlinear strain-displacement of Von Karman relations are also taken into consideration. The boundary conditions for the plate are assumed to be simply supported in all edges. Closed-form solutions are presented to calculate the critical load of mechanical buckling, which are useful for engineers in design. The effects of the foundation parameters, side-to-thickness ratio and modulus ratio, the isotropic and orthotropic square plates are presented comprehensively for the mechanical buckling of rectangular composite plates.
\end{abstract}

KEYWORDS. Rectangular composite plate; Critical buckling load; Refined shear theory; Elastic foundation; Non-linear relations of Vont Karman.

\section{OPEN ACCESS}

Citation: Khalfi, Y, Bouchiki, A, S., Bellebna, Y., Mechanical stability investigation of advanced composite plates resting on elastic foundations using a new four-unknown refined theory, Frattura ed Integrità Strutturale, 48 (2019) 208-221.

Received: 20.01.2019

Accepted: 12.02 .2019

Published: 01.04.2019

Copyright: (C) 2019 This is an open access article under the terms of the CC-BY 4.0, which permits unrestricted use, distribution, and reproduction in any medium, provided the original author and source are credited. 


\section{INTRODUCTION}

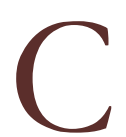

omposite materials have important advantages over traditional materials. They bring many functional advantages: lightness, mechanical and chemical resistance, reduced maintenance, freedom of forms. They make it possible to increase the lifespan of certain equipment thanks to their mechanical and chemical properties. They contribute to the reinforcement of safety thanks to a better resistance to shocks and fire. They offer better thermal or sound insulation and, for some of them, good electrical insulation. They also enrich the design possibilities by lightening structures and making complex shapes, able to fulfill several functions. In each of the application markets (automotive, building, electricity, industrial equipment, etc.), these remarkable performances are at the origin of innovative technological solutions [1]. They constitute one of the most advanced class of materials whose popularity in industrial applications keeps growing exponentially [2]. Their advent has been aided by the development of new processing methods, theoretical approaches of homogenization [3,4] and numerical simulations of heterogeneous materials [5]. This class of materials is commonly divided into three categories [6] : (i) fibrous composites consisting of continuous fibers embedded in a matrix, (ii)laminated composites consisting of various stacked layers, and (iii) particle-reinforced composites composed of particles in a matrix. The buckling of rectangular plates has been a subject of study in solid mechanics for more than a century. Many exact solutions for isotropic and orthotropic plates have been developed, most of them can be found in Timoshenko and Woinowsky-Krieger [7], Timoshenko and Gere [8], Bank and Jin [9], Kang and Leissa [10], Aydogdu and Ece [11], and Hwang and Lee [12]. In company with studies of buckling behavior of plate, many plate theories have been developed. The simplest one is the classical plate theory (CPT) which neglects the transverse normal and shear stresses. This theory is not appropriate for the thick and orthotropic plate with high degree of modulus ratio. In order to overcome this limitation, the shear deformable theory which takes account of transverse shear effects is recommended. The Reissner [13] and Mindlin [14] theories are known as the first-order shear deformation theory (FSDT), and account for the transverse shear effects by the way of linear variation of in-plane displacements through the thickness. However, these models do not satisfy the zero traction boundary conditions on the top and bottom faces of the plate, and need to use the shear correction factor to satisfy the constitutive relations for transverse shear stresses and shear strains. For these reasons, many higher-order theories have been developed to improve in FSDT such as Levinson [15] and Reddy [16]. Shimpi and Patel [17] presented a four variable refined plate theory (RPT) for orthotropic plates. This theory which looks like higher-orde theory uses only four unknown functions in order to derive two governing equations for orthotropic plates. The most interesting feature of this theory is that it does not require shear correction factor, and has strong similarities with the CPT in some aspects such as governing equation, boundary conditions and moment expressions. The accuracy of this theory has been demonstrated for static bending and free vibration behaviors of plates by Shimpi and Patel [17], therefore, it seems to be important to extend this theory to the static buckling behavior.

In this paper, the four variable RPT developed by Shimpi and Patel [17] has been extended to the buckling behavior of isotropic and orthotropic plate resting on two-parameter Pasternak's foundations subjected to the in-plane loading. Using the Navier method, the closed-form solutions have been obtained. Numerical examples involving side-to-thickness ratio, effects of the foundation parameters and modulus ratio are presented to illustrate the accuracy of the present theory in predicting the critical buckling load of isotropic and orthotropic plates. The numerical results obtained by the present theory are compared with solutions of classical theory (CPT) and solutions of first order shear deformation theory (FSDT) and high order shear theory (HSDT).

\section{MATHEMATICAL FORMULATION}

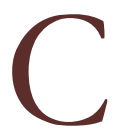

onsider a rectangular composite plate of thickness $b$, length $a$ and width $b$, referred to the rectangular Cartesian coordinate system $(x, y, z)$, as shown in Fig 1 . Since in this type of plates there is material symmetry with respect to the median plane (the origin of the coordinate system is appropriately chosen in the direction of the thickness of the composite plate so that it will be confused with the neutral surface) the equations of membranes and bending will be decoupled and therefore equilibrium equations [18].

Based on the refined theory of shear deformation [19], the displacement field can be written as:

$$
\begin{aligned}
& u(x, y, z)=u_{0}(x, y)-z \frac{\partial w_{b}}{\partial x}+f(z) \frac{\partial w_{s}}{\partial x} \\
& v(x, y, z)=v_{0}(x, y)-z \frac{\partial w_{b}}{\partial y}+f(z) \frac{\partial w_{s}}{\partial y}
\end{aligned}
$$




$$
w(x, y)=w_{b}(x, y)+w_{s}(x, y)
$$

where $u_{0}$ and $v_{0}$ are the mid-plane displacements of the plate in the $\mathrm{x}$ and y direction, respectively; $w_{b}$ and $w_{s}$ are the bending and shear components of transverse displacement, respectively.

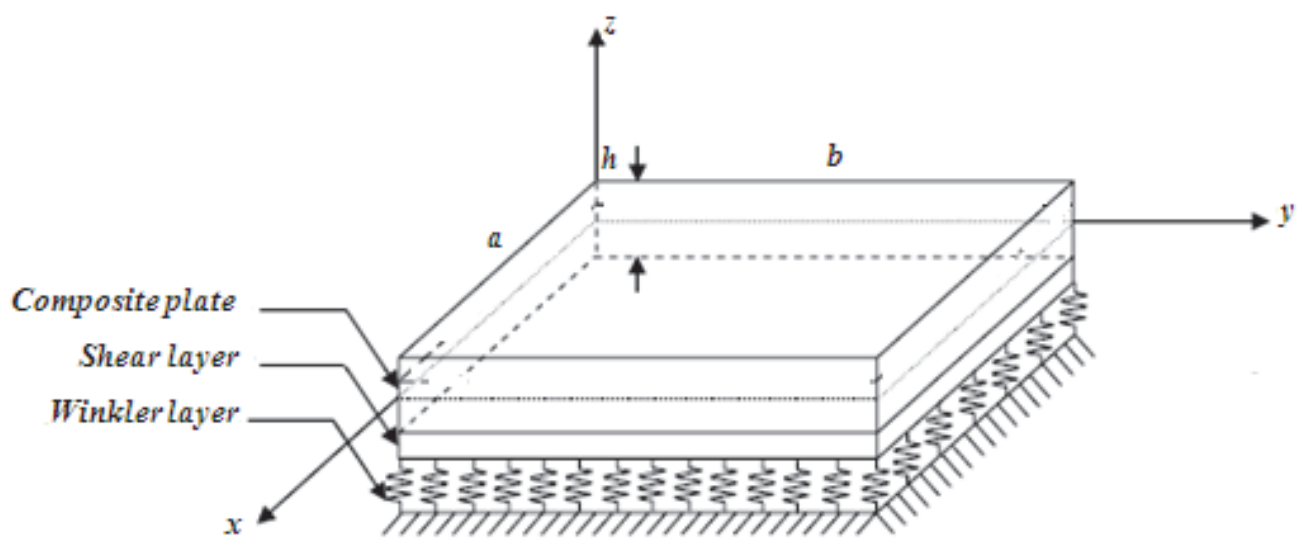

Figure 1: Coordinate system and geometry for rectangular composite plate on Pasternak elastic foundation.

This displacement field verifies the nullity of traction boundary conditions on the top and bottom faces of the plate, and leads to a quadratic variation of transverse shear deformations (and therefore stresses) across the thickness. Thus, it is not necessary to use shear correction factors. The nonlinear deformation-displacement equations of Von Karman are as follows:

$$
\left\{\begin{array}{l}
\varepsilon_{x} \\
\varepsilon_{y} \\
\gamma_{x y}
\end{array}\right\}=\left\{\begin{array}{c}
\varepsilon_{x}^{0} \\
\varepsilon_{y}^{0} \\
\gamma_{x y}^{0}
\end{array}\right\}+z\left\{\begin{array}{l}
k_{x}^{b} \\
k_{y}^{b} \\
k_{x y}^{b}
\end{array}\right\}+f(z)\left\{\begin{array}{c}
k_{x}^{s} \\
k_{y}^{s} \\
k_{x y}^{s}
\end{array}\right\},\left\{\begin{array}{l}
\gamma_{y z} \\
\gamma_{x z}
\end{array}\right\}=g(z)\left\{\begin{array}{l}
\gamma_{y z}^{s} \\
\gamma_{y z}^{s}
\end{array}\right\}
$$

where

$$
\begin{aligned}
& \varepsilon_{x}^{0}=\frac{\partial u_{0}}{\partial x}+\frac{1}{2}\left(\frac{\partial w_{b}}{\partial x}+\frac{\partial w_{s}}{\partial x}\right)^{2}, k_{x}^{b} \frac{\partial^{2} w_{b}}{\partial x^{2}}, k_{x}^{s} \frac{\partial^{2} w_{s}}{\partial x^{2}} \\
& \varepsilon_{y}^{0}=\frac{\partial v_{0}}{\partial y}+\frac{1}{2}\left(\frac{\partial w_{b}}{\partial y}+\frac{\partial w_{s}}{\partial y}\right)^{2}, k_{x}^{b}=\frac{\partial^{2} w_{b}}{\partial y^{2}}, k_{x}^{s}=\frac{\partial^{2} w_{s}}{\partial y^{2}} \\
& \gamma_{x y}^{0}=\frac{\partial u_{0}}{\partial y}+\frac{\partial v_{0}}{\partial x}+\left(\frac{\partial w_{b}}{\partial x}+\frac{\partial w_{s}}{\partial x}\right)\left(\frac{\partial w_{b}}{\partial y}+\frac{\partial w_{s}}{\partial y}\right) \\
& k_{x y}^{b}=-2 \frac{\partial^{2} w_{b}}{\partial y^{2}}, k_{x y}^{s}=-2 \frac{\partial^{2} w_{s}}{\partial y^{2}} \\
& \gamma_{y z}^{s}=\frac{\partial w_{s}}{\partial y}, \gamma_{x z}^{s}=\frac{\partial w_{s}}{\partial x}, f(z)=\frac{(h / \pi) \sinh \left(\frac{\pi}{h} z\right)-z}{\cosh (\pi / h)-1} \\
& g(z)=1-f^{\prime}(z), f^{\prime}(z)=\frac{\partial f(z)}{\partial z}
\end{aligned}
$$

The linear constitutive relations of a composite plate can be written as 


$$
\left\{\begin{array}{l}
\sigma_{x} \\
\sigma_{y} \\
\tau_{x y} \\
\tau_{y z} \\
\tau_{x z}
\end{array}\right\}=\left[\begin{array}{ccccc}
Q_{12} & Q_{22} & 0 & 0 & 0 \\
Q_{12} & Q_{22} & 0 & 0 & 0 \\
0 & 0 & Q_{66} & 0 & 0 \\
0 & 0 & 0 & Q_{44} & 0 \\
0 & 0 & 0 & 0 & Q_{55}
\end{array}\right]\left\{\begin{array}{l}
\varepsilon_{x} \\
\varepsilon_{y} \\
\gamma_{x y} \\
\gamma_{y z} \\
\gamma_{x z}
\end{array}\right\}
$$

where $\left(\sigma_{x}, \sigma_{y}, \tau_{x y}, \tau_{y \xi}, \tau_{y x}\right)$ and $\left(\varepsilon_{x}, \varepsilon_{y}, \gamma_{x y}, \gamma_{y 2}, \gamma_{y x}\right)$ are the stress and strain components, respectively. $Q_{i j}$ are the elements of the reduced stiffness matrix that are defined as follows:

$$
Q_{11}=\frac{E_{1}}{1-v_{12} v_{21}}, Q_{12}=\frac{v_{12} E_{2}}{1-v_{12} v_{21}}, Q_{22}=\frac{E_{2}}{1-v_{12} v_{21}}, Q_{66}=G_{12}, Q_{44}=G_{23}, Q_{55}=G_{13}
$$

Based on the present refined shear plate theory, the stress resultants are related to the stresses by the equations [19]

$$
\begin{aligned}
& \left\{\begin{array}{lll}
N_{x} & N_{y} & N_{x y} \\
M_{x}^{b} & M_{y}^{b} & M_{x y}^{b} \\
M_{x}^{s} & M_{y}^{s} & M_{x y}^{s}
\end{array}\right\}=\int_{-h / 2}^{h / 2}\left(\sigma_{x}, \sigma_{y}, \tau_{x y}\right)\left\{\begin{array}{l}
1 \\
z \\
f(z)
\end{array}\right\} d z \\
& \left(S_{x z}^{s}, S_{y z}^{s}\right)=\int_{-h / 2}^{h / 2}\left(\tau_{x z}, \tau_{y z}\right) g(z) d z
\end{aligned}
$$

Using Eq. (4) in Eq. (6), the stress resultants of the can be related to the total strains by

$$
\left\{\begin{array}{c}
N \\
M^{b} \\
M^{s}
\end{array}\right\}=\left[\begin{array}{ccc}
A & 0 & B^{s} \\
0 & D & D^{s} \\
B^{s} & D^{s} & H^{s}
\end{array}\right]\left\{\begin{array}{c}
\varepsilon \\
k^{b} \\
k^{s}
\end{array}\right\}, S=A^{s} \gamma
$$

where

$$
\begin{aligned}
& N=\left\{N_{x}, N_{y}, N_{x y}\right\}^{t}, M^{b}=\left\{M_{x}^{b}, M_{y}^{b}, M_{x y}^{b}\right\}^{t} M^{s}=\left\{M_{x}^{s}, M_{y}^{s}, M_{x y}^{s}\right\}^{t} \\
& \varepsilon=\left\{\varepsilon_{x}^{0}, \varepsilon_{y}^{0}, \varepsilon_{x y}^{0}\right\}^{t}, k^{b}=\left\{k_{x}^{b}, k_{y}^{b}, k_{x y}^{b}\right\}^{t}, k^{s}=\left\{k_{x}^{s}, k_{y}^{s}, k_{x y}^{s}\right\}^{t} \\
& A=\left[\begin{array}{ccc}
A_{11} & A_{12} & 0 \\
A_{12} & A_{22} & 0 \\
0 & 0 & A_{66}
\end{array}\right], D=\left[\begin{array}{ccc}
D_{11} & D_{12} & 0 \\
D_{12} & D_{22} & 0 \\
0 & 0 & D_{66}
\end{array}\right] \\
& B^{s}=\left[\begin{array}{ccc}
B_{11}^{s} & B_{12}^{s} & 0 \\
B_{12}^{s} & B_{22}^{s} & 0 \\
0 & 0 & B_{66}^{s}
\end{array}\right], D^{s}=\left[\begin{array}{ccc}
D_{11}^{s} & D_{12}^{s} & 0 \\
D_{12}^{s} & D_{22}^{s} & 0 \\
0 & 0 & D_{66}^{s}
\end{array}\right], H^{s}=\left[\begin{array}{ccc}
H_{11}^{s} & H_{12}^{s} & 0 \\
H_{12}^{s} & H_{22}^{s} & 0 \\
0 & 0 & H_{66}^{s}
\end{array}\right] \\
& S=\left\{S_{y z}^{s}, S_{x z}^{s}\right\}^{t}, \gamma=\left\{\gamma_{y z}, \gamma_{x z}\right\}^{t}, A^{s}=\left[\begin{array}{cc}
A_{44}^{s} & 0 \\
0 & A_{55}^{s}
\end{array}\right]
\end{aligned}
$$


where $A_{i j} D_{i j}$, etc., are the plate stiffness, defined by

$$
\begin{aligned}
& \left\{\begin{array}{lllll}
A_{11} & D_{11} & B_{11}^{s} & D_{11}^{s} & H_{11}^{s} \\
A_{12} & D_{12} & B_{12}^{s} & D_{12}^{s} & H_{12}^{s} \\
A_{66} & D_{66} & B_{66}^{s} & D_{66}^{s} & H_{66}^{s}
\end{array}\right\}=\int_{-h / 2}^{h / 2}\left[\begin{array}{l}
Q_{11}\left(1, z^{2}, f(z), z f(z), f^{2}(z)\right) \\
Q_{12}\left(1, z^{2}, f(z), z f(z), f^{2}(z)\right) \\
Q_{66}\left(1, z^{2}, f(z), z f(z), f^{2}(z)\right)
\end{array}\right] d z \\
& \left(A_{22}, D_{22}, B_{22}^{s}, D_{22}^{s}, H_{22}^{s}\right)=\left(A_{11}, D_{11}, B_{11}^{s}, D_{11}^{s}, H_{11}^{s}\right) \\
& A_{44}^{s}=A_{55}^{s}=\int_{/ h / 2}^{h / 2} Q 44[g(z)] d z
\end{aligned}
$$

\section{EQUILIBRIUM AND STABILITY EQUATIONS}

$\mathrm{T}$

he equilibrium equations of the rectangular composite plate resting on the Pasternak elastic foundation under mechanical loadings may be derived on the basis of the stationary potential energy. The total potential energy of the plate, $\mathrm{V}$, may be written in the form

$$
V=U+U_{F}
$$

Here, $U$ is the total strain energy of the plate, and is calculated as

$$
U=\frac{1}{2} \int_{0}^{a} \int_{0}^{b} \int_{-h / 2}^{h / 2}\left[\sigma_{x} \varepsilon_{x}+\sigma_{y} \varepsilon_{y}+\tau_{x y} \gamma_{x y}+\tau_{y z} \gamma_{y z}+\tau_{x z} \gamma_{x z}\right] d z d y d x
$$

and $U_{f}$ is the strain energy due to the Pasternak elastic foundation, which is given by [20]

$$
U_{f}=\frac{1}{2} \int_{0}^{a} \int_{0}^{b} f_{e}\left(w_{b}+w_{s}\right) d y d x
$$

where fe is the density of reaction force of foundation. For the Pasternak foundation model:

$$
f_{e}=K_{W}\left(w_{b}+w_{s}\right)-K_{g} \nabla^{2}\left(w_{b}+w_{s}\right)
$$

where $K_{W}$ is the Winkler foundation stiffness and $K_{g}$ is a constant showing the effect of the shear interactions of the vertical elements.

Using Eqs. (2), (3), and (7) and employing the virtual work principle to minimize the functional of total potential energy function result in the expressions for the equilibrium equations of plate resting on two parameters elastic foundation as

$$
\begin{aligned}
& \frac{\partial N_{x}}{\partial x}+\frac{\partial N_{x y}}{\partial y}=0 \\
& \frac{\partial N_{x y}}{\partial x}+\frac{\partial N_{y}}{\partial y}=0 \\
& \frac{\partial^{2} M_{x}^{b}}{\partial x^{2}}+2 \frac{\partial^{2} M_{x y}^{b}}{\partial x \partial y}+\frac{\partial^{2} M_{y}^{b}}{\partial y^{2}}+\bar{N}-f_{e}=0
\end{aligned}
$$




$$
\frac{\partial^{2} M_{x}^{s}}{\partial x^{2}}+2 \frac{\partial^{2} M_{x y}^{s}}{\partial x \partial y}+\frac{\partial^{2} M_{y}^{s}}{\partial y^{2}}+\frac{\partial S_{x z}^{s}}{\partial x}+\frac{\partial S_{y z}^{s}}{\partial y}+\bar{N}-f_{e}=0
$$

where

$$
\bar{N}=\left[N x \frac{\partial^{2}\left(w_{b}+w_{s}\right)}{\partial x^{2}}+2 N_{x y} \frac{\partial^{2}\left(w_{b}+w_{s}\right)}{\partial x \partial y}+N y \frac{\partial^{2}\left(w_{b}+w_{s}\right)}{\partial y^{2}}\right]
$$

The stability equations in terms of displacement can be obtained by substituting equation (7) in equation (15). The equations obtained based on the present theory of refined shear deformation of the composite plates resting on two-parameter elastic foundation are four in number and are as follows:

$$
\begin{aligned}
& A_{11} \frac{\partial^{2} u_{0}}{\partial x^{2}}+A_{66} \frac{\partial^{2} u_{0}}{\partial y^{2}}+\left(A_{12}+A_{66}\right) \frac{\partial^{2} v_{0}}{\partial x \partial y}-B_{11}^{s} \frac{\partial^{3} w_{s}}{\partial x^{3}}-\left(B_{12}^{s}+2 B_{66}^{s}\right) \frac{\partial^{3} w_{s}}{\partial x \partial y^{2}}=0 \\
& \left(A_{12}+A_{66}\right) \frac{\partial^{2} u_{0}}{\partial x \partial y}+A_{66} \frac{\partial^{2} v_{0}}{\partial x^{2}}+A_{22} \frac{\partial^{2} v_{0}}{\partial y^{2}}-B_{22}^{s} \frac{\partial^{3} w_{s}}{\partial y^{3}}-\left(B_{12}^{s}+2 B_{66}^{s}\right) \frac{\partial^{3} w_{s}}{\partial x^{2} \partial y}=0 \\
& -D_{11} \frac{\partial^{4} w_{b}}{\partial x^{4}}-2\left(D_{12}+2 D_{66}\right) \frac{\partial^{4} w_{b}}{\partial x^{2}+\partial y^{2}}-D_{22} \frac{\partial^{4} w_{b}}{\partial y^{4}}-D_{11}^{s} \frac{\partial^{4} w_{s}}{\partial x^{4}}-2\left(D_{12}^{s}+2 D_{66}^{s}\right) \frac{\partial^{4} w_{s}}{\partial x^{2} \partial y^{2}}-D_{22}^{s} \frac{\partial^{4} w_{s}}{\partial y^{4}} \\
& -K_{W}\left(w_{b}+w_{s}\right)+K_{g} \nabla^{2}\left(w_{b}+w_{s}\right)+\bar{N}=0 \\
& B_{11}^{s} \frac{\partial^{3} u_{0}}{\partial x^{3}}+\left(B_{12}^{s}+2 B_{66}^{s}\right) \frac{\partial^{3} u_{0}}{\partial x \partial y^{2}}+\left(B_{12}^{s}+2 B_{66}^{s}\right) \frac{\partial^{3} v_{0}}{\partial x^{2} \partial y}+B_{22}^{s} \frac{\partial^{3} v_{0}}{\partial y^{3}}-D_{11}^{s} \frac{\partial^{4} w_{b}}{\partial x^{4}}-2\left(D_{12}^{s}+2 D_{66}^{s}\right) \frac{\partial^{4} w_{b}}{\partial x^{2} \partial y^{2}} \\
& -D_{22}^{s} \frac{\partial^{4} w_{b}}{\partial y^{4}}-H_{11}^{s} \frac{\partial^{4} w_{s}}{\partial x^{4}}-2\left(H_{12}^{s}+2 H_{66}^{s}\right) \frac{\partial^{4} w_{s}}{\partial x^{2} \partial y^{2}}-H_{22}^{s} \frac{\partial^{4} w_{s}}{\partial y^{4}}+A_{55}^{s} \frac{\partial^{2} w_{s}}{\partial x^{2}}+A_{44}^{s} \frac{\partial^{2} w_{s}}{\partial y^{2}}-K_{W}\left(w_{b}+w_{s}\right) \\
& +K_{g} \nabla^{2}\left(w_{b}+w_{s}\right)+\bar{N}=0
\end{aligned}
$$

\section{Trigonometric Solution to Mechanical BUCKLING}

$\mathrm{R}$

ectangular plates are generally classified in accordance with the type of support. We are here concerned with the exact solution of Eq. (17) for a simply supported rectangular composite plate (Figure 2a). The following boundary conditions are imposed for the present refined shear deformation theory at the side edges [21]:

$$
\begin{aligned}
& v_{0}=w_{b}=w_{s}=\frac{\partial w_{s}}{\partial y}=N_{x}=M_{x}^{b}=M_{x}^{s} \quad \text { at } x=0, a \\
& u_{0}=w_{b}=w_{s}=\frac{\partial w_{s}}{\partial y}=N_{y}=M_{y}^{b}=M_{y}^{s} \quad \text { at } \quad y=0, b
\end{aligned}
$$

The following approximate solution is seen to satisfy both the differential equation and the boundary conditions

$$
\left\{\begin{array}{l}
u_{0} \\
v_{0} \\
w_{b} \\
w_{s}
\end{array}\right\}=\sum_{m=1}^{\infty} \sum_{n=1}^{\infty}\left\{\begin{array}{l}
U_{m n} \cos (\lambda x) \sin (\mu y) \\
V_{m n} \cos (\lambda x) \sin (\mu y) \\
W_{b m n} \sin (\lambda x) \sin (\mu y) \\
W_{s m n} \sin (\lambda x) \sin (\mu y)
\end{array}\right\}
$$

where $U_{m n}, V_{m n}, W_{b m n}$, and $W_{s m n}$ are arbitrary parameters to be determined and $\lambda=m \pi / a$ and $\mu=n \pi / b$. Substituting Eq. (19) into Eq. (17), one obtains 


$$
[K]\{\Delta\}=0
$$

where $\{\Delta\}$ denotes the column

$$
\{\Delta\}=\left\{U_{m n}, V_{m n}, W_{b m n}, W_{s m n}\right\}^{t}
$$

and $[K]$ is the symmetric matrix given by

$$
[K]=\left[\begin{array}{llll}
a_{11} & a_{12} & a_{13} & a_{14} \\
a_{12} & a_{22} & a_{23} & a_{24} \\
a_{13} & a_{23} & a_{33} & a_{34} \\
a_{14} & a_{24} & a_{34} & a_{44}
\end{array}\right]
$$

a

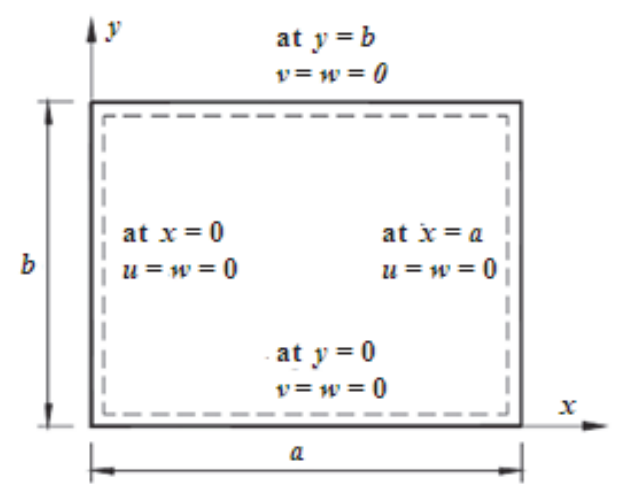

Figure 2: Rectangular plate: (a) boundary condition and (b) in-plane forces.

\section{$N_{y}{ }^{0}$}

b

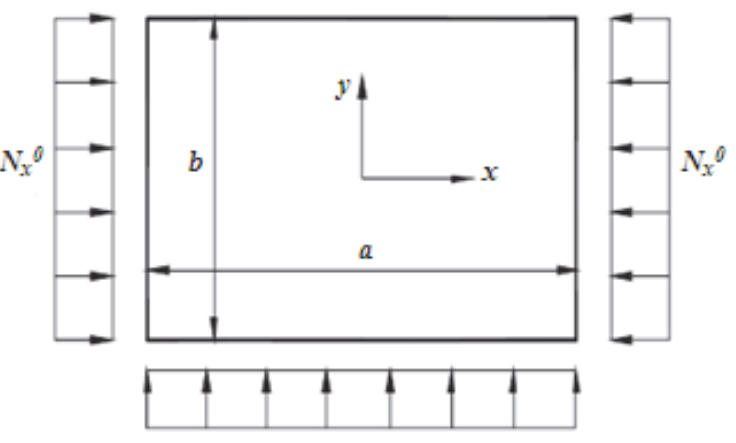

in which

$$
\begin{aligned}
& a_{11}=-\left(A_{11} \lambda^{2}+A_{66} \mu^{2}\right) \\
& a_{12}=-\lambda \mu\left(A_{12}+A_{66}\right) \\
& a_{13}=0 \\
& a_{14}=\lambda\left[B_{11}^{s} \lambda^{2}+\left(B_{12}^{s}+2 B_{66}^{s}\right) \mu^{2}\right] \\
& a_{22}=-\left(A_{66} \lambda^{2}+A_{22} \mu^{2}\right) \\
& a_{23}=0 \\
& a_{24}=\mu\left[\left(B_{12}^{s}+2 B_{66}^{s}\right) \lambda^{2}+B_{22}^{s} \mu^{2}\right] \\
& a_{33}=-\left(D_{11} \lambda^{4}+2\left(D_{12}+2 D_{66}\right) \lambda^{2} \mu^{2}+D_{22} \mu^{4}+N_{x}^{0} \lambda^{2}+N_{y}^{0} \mu^{2}+K_{g}\left(\lambda^{2}+\mu^{2}\right)+K_{W}\right) \\
& a_{34}=-\left(D_{11}^{s} \lambda^{4}+2\left(D_{12}^{s}+2 D_{66}^{s}\right) \lambda^{2} \mu^{2}+D_{22}^{s} \mu^{4}+N_{x}^{0} \lambda^{2}+N_{y}^{0} \mu^{2}+K_{g}\left(\lambda^{2}+\mu^{2}\right)+K_{W}\right)
\end{aligned}
$$




$$
a_{44}=-\left(H_{11}^{s} \lambda^{4}+2\left(H_{12}^{s}+2 H_{66}^{s}\right) \lambda^{2} \mu^{2}+H_{22}^{s} \mu^{4}+A_{55}^{s} \lambda^{2}+A_{44}^{s} \mu^{2}+N_{x}^{0} \lambda^{2}+N_{y}^{0} \mu^{2}+K_{g}\left(\lambda^{2}+\mu^{2}\right)+K_{W}\right)
$$

By applying the static condensation approach to eliminate the coefficients associated with the in-plane displacements, Eq. (20) can be rewritten as

$$
\left[\begin{array}{cc}
{\left[K_{11}\right]} & {\left[K^{12}\right]} \\
{\left[K^{12}\right]^{T}} & {\left[K^{22}\right]}
\end{array}\right]\left\{\begin{array}{l}
\Delta^{1} \\
\Delta^{2}
\end{array}\right\}=\left\{\begin{array}{l}
0 \\
0
\end{array}\right\}
$$

where

$$
\begin{aligned}
& {\left[K^{11}\right]=\left[\begin{array}{ll}
a_{11} & a_{12} \\
a_{12} & a_{22}
\end{array}\right],\left[K^{12}\right]=\left[\begin{array}{ll}
0 & a_{14} \\
0 & a_{24}
\end{array}\right],\left[K^{22}\right]=\left[\begin{array}{ll}
a_{33} & a_{34} \\
a_{34} & a_{44}
\end{array}\right]} \\
& \Delta^{1}=\left\{\begin{array}{l}
U_{m n} \\
V_{m n}
\end{array}\right\}, \Delta^{2}=\left\{\begin{array}{l}
W_{b m n} \\
W_{s m n}
\end{array}\right\}
\end{aligned}
$$

Equation (24) represents a pair of two matrix equations:

$$
\begin{aligned}
& {\left[K^{11}\right] \Delta^{1}+\left[K^{12}\right] \Delta^{2}=0} \\
& {\left[K^{12}\right]^{T} \Delta^{1}+\left[K^{22}\right] \Delta^{2}=0}
\end{aligned}
$$

Solving Eq. (26a) for $\Delta^{1}$ and then substituting the result into Eq. (26b), the following equation is obtained:

$$
\left[\bar{K}^{22}\right] \Delta^{2}=0
$$

where

$$
\left[\bar{K}^{22}\right]=\left[K^{22}\right]-\left[K^{12}\right]^{T}\left[K^{11}\right]^{-1}\left[K^{12}\right]=\left[\begin{array}{ll}
a_{33} & a_{34} \\
a_{34} & b_{44}
\end{array}\right]
$$

and

$$
\begin{aligned}
& \bar{a}_{33}=a_{33}, \bar{a}_{34}=a_{34} \\
& \bar{a}_{43}=a_{34}, b_{44}=a_{44}-a_{14} \frac{b_{1}}{b_{0}}-a_{24} \frac{b_{2}}{b_{0}} \\
& b_{0}=a_{11} a_{22}-a_{12}^{2}, b_{1}=a_{14} a_{22}-a_{12} a_{24}, b_{2}=a_{11} a_{24}-a_{12} a_{14},
\end{aligned}
$$

For nontrivial solution, the determinant of the coefficient matrix in Eq. (27) must be zero. This gives the following expression for the mechanical buckling load

$$
N_{x}^{0}=N_{y}^{0}=\frac{1}{\lambda^{2}+\mu^{2}} \frac{a_{33} b_{44}-a_{34}^{2}}{a_{33}+a_{44}-2 a_{34}}
$$


Clearly, when the effect of transverse shear deformation is neglected, the Eq.(29) yields the result obtained using the classical plate theory [22]. It indicates that transverse shear deformation has the effect of reducing the buckling load. For each choice of $m$ and $n$, there is a corresponsive unique value of $N_{0}$. The critical buckling load is the smallest value of $N_{0}(m, n)$.

\section{RESULTS AND DISCUSSION}

$\mathrm{T}$

o illustrate the proposed theory, a simply supported rectangular plate subjected to the different types of loading (or even Figure.2), is considered to verify the accuracy of the current theory in the prediction of the critical loads of the mechanical buckling of rectangular composite plates. Comparisons are made with different plate theories available in the literature The description of the different displacement models is given in Table 1. In order to study the effects of the parameters of the foundation, side-to-thickness ratio $(a / h)$ and the modulus ratios $\left(E_{1} / E_{2}\right)$, isotropic square plates and orthotropes are considered. The shear correction factor $(\mathrm{k}=5 / 6)$ and also used for the first order shear deformation theory (FSDT) and a comparison with the current theory is established.

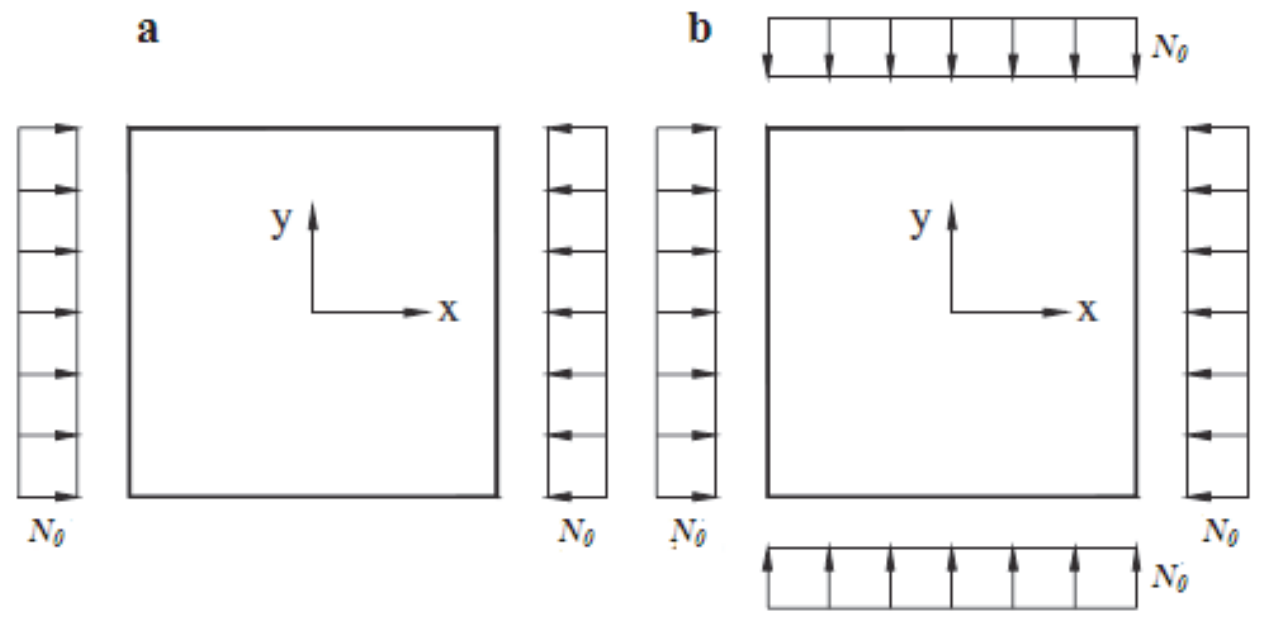

Figure 3: The loading conditions of square plate for (a) uniaxial compression, (b) biaxial compression.

\begin{tabular}{llc}
\hline Model & Theory & $\begin{array}{c}\text { Unknown } \\
\text { functions }\end{array}$ \\
CPT & Classical plate theory & 3 \\
FSDT & First-order shear deformation theory [23] & 5 \\
HSDT & Higer order shear deformation theory [24] & 5 \\
Present & Present refined plate theory & 4 \\
\hline
\end{tabular}

Table 1: Displacement models.

It is assumed that the thickness and properties of materials for all laminates are the same.

The following engineer constants are used [25]:

- for isotropic rectangular plates:

$E_{1}=E_{2}=E, G_{12}=G_{13}=G_{23}=G=E / 2(1+v), v_{12}=v_{13}=v_{23}=v=0.3$

- For orthotropic rectangular plates:

$$
E_{1}=E_{2} \text { varied, } G_{12} / E_{2}=G_{13} / E_{2}=0.5, G_{23} / E_{2}=0.2, \nu_{12}=0.25, v_{21}:=\left(\nu_{12} E_{2}\right) / E_{1}
$$

For convenience, the following nondimensional buckling load is used: 


$$
\bar{N}=\frac{N_{c r} a^{2}}{E_{2} h^{3}}
$$

where $a$ is the length of the square plate and $b$ is the thickness of the plate.

The following dimensionless of Winkler's and Pasternak's elastic foundation parameters, as well as the critical buckling temperature difference are used in the present analysis

$$
k_{1}=\frac{a^{4}}{D} K_{W}, k_{2}=\frac{a^{4}}{D} K_{g}
$$

where

$$
D=E_{2} h^{3} /\left[12\left(1-v^{2}\right)\right]
$$

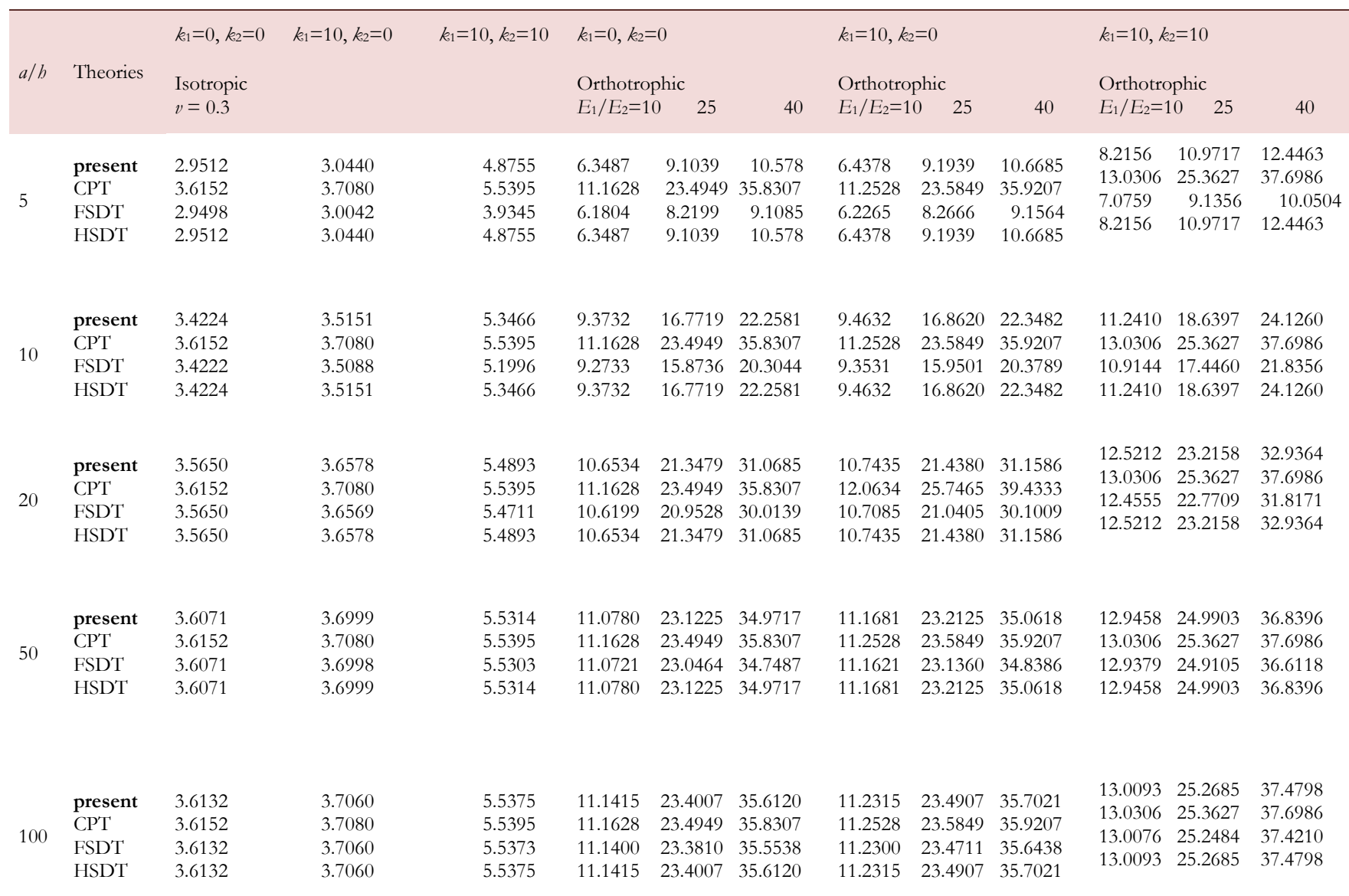

Table 2: Comparison of nondimensional critical buckling load of square plates subjected to uniaxial compression.

In order to verify the mechanical buckling solutions determined in this work, the results of composite plates under uniaxial and biaxial loading are obtained and compared with those predicted by CPT, FSDT, and HSDT as indicated in Tables 2 and 3.It is clear that the results show significant differences between the shear deformation theories and the classical plate theory, due to the shear deformation effect. In addition, an excellent agreement is obtained between the current theory and the HSDT for all side-to-thickness ratio values $a / h$ and the modulus ratios $E_{1} / E_{2}$. The disagreement between the present theory RPT and HSDT on the one hand and the first order shear theory FSDT on the other hand increases as the side-tothickness $a / h$ and the modulus ratios $E_{1} / E_{2}$ increases. It can also be noted that the dimensionless critical load of buckling increases rapidly with the increase of the side-to-thickness ratio $a / h$, while this dimensionless load ceases to increase when 
this ratio exceeds 25 (the plate becomes thinner more and more), and the results obtained by shear deformation theories (current RPT theory and first-order shear theory FSDT and high order theory HSDT) become identical to that obtained by conventional CPT theory, implying that the effect transverse shear becomes useless. Indeed, the non dimensional critical load of the buckling does not depend on the variation of side-to-thickness according to the classical theory which neglects the effect of the transverse shear. It is clear to note the considerable increase in dimensionless critical load of buckling when the plate rests on an elastic foundation. It should be noted that the unknown function in present theory is 4, while the unknown function in FSDT and HSDT is 5. It can be concluded that the present theory is not only accurate but also simple in predicting the critical buckling load of rectangular composite plates.

\begin{tabular}{|c|c|c|c|c|c|c|c|c|c|c|c|c|c|}
\hline \multirow{3}{*}{$a / b$} & \multirow{3}{*}{ Theories } & \multirow{3}{*}{$\begin{array}{l}k_{1}=0, k_{2}=0 \\
\text { Isotropic } \\
v=0.3\end{array}$} & \multirow[t]{3}{*}{$k_{1}=10, k_{2}=0$} & \multirow[t]{3}{*}{$k_{1}=10, k_{2}=10$} & \multicolumn{3}{|l|}{$k_{1}=0, k_{2}=0$} & \multicolumn{3}{|c|}{$k_{1}=10, k_{2}=0$} & \multicolumn{3}{|c|}{$k_{1}=10, k_{2}=10$} \\
\hline & & & & & \multicolumn{3}{|c|}{ Orthotrophic } & \multicolumn{3}{|c|}{ Orthotrophic } & \multicolumn{3}{|c|}{ Orthotrophic } \\
\hline & & & & & $E_{1} / E_{2}=10$ & 25 & 40 & $E_{1} / E_{2}=10$ & 25 & 40 & $E_{1} / E_{2}=10$ & $0 \quad 25$ & 40 \\
\hline \multirow{4}{*}{5} & present & 1.4756 & 1.5220 & 2.4378 & 2.8549 & 3.3309 & 3.4800 & $2.8729^{\mathrm{a}}$ & $3.3489^{a}$ & $3.6905^{\mathrm{a}}$ & 4.1078 & $4.2378^{\mathrm{a}}$ & $4.5794^{a}$ \\
\hline & СРT & 1.8076 & 1.8540 & 2.7698 & 5.5814 & 8.4069 & 10.8715 & 5.6264 & $8.4249^{a}$ & $10.8895^{\mathrm{a}}$ & 6.5153 & $9.3138^{\mathrm{a}}$ & $11.7783^{\mathrm{a}}$ \\
\hline & FSDT & 1.4749 & 1.5070 & 2.1138 & 2.8319 & 3.1422 & 3.2822 & $2.8341^{\mathrm{a}}$ & $3.1453^{\mathrm{a}}$ & $3.2859^{\mathrm{a}}$ & $2.9976^{\mathrm{a}}$ & $3.3390^{\mathrm{a}}$ & $3.4994^{\mathrm{a}}$ \\
\hline & HSDT & 1.4756 & 1.5220 & 2.4378 & 2.8549 & 3.3309 & 3.4800 & $2.8729 \mathrm{a}$ & $3.3489^{a}$ & $3.6905 a$ & 4.1078 & $4.2378^{a}$ & $4.5794^{\mathrm{a}}$ \\
\hline \multirow{4}{*}{10} & present & 1.7112 & 1.7576 & 2.6733 & 4.6718 & $6.0646^{\mathrm{a}}$ & 7.2536 & $4.6898^{a}$ & $6.0826^{\mathrm{a}}$ & $7.2716^{\mathrm{a}}$ & $5.5787^{\mathrm{a}}$ & $6.9714^{a}$ & $8.1604^{a}$ \\
\hline & СРT & 1.8076 & 1.8540 & 2.7698 & 5.5814 & 8.4069 & 10.8715 & 5.6264 & $8.4249^{a}$ & $10.8895^{\mathrm{a}}$ & 6.5153 & $9.3138^{\mathrm{a}}$ & $11.7783^{a}$ \\
\hline & FSDT & 1.7111 & 1.7552 & 2.6208 & 4.6367 & 5.8370 & 6.6325 & 4.6765 & 5.8491 a & $6.6444^{a}$ & $5.2882 \mathrm{a}$ & $6.4367 a$ & $7.2181^{\mathrm{a}}$ \\
\hline & HSDT & 1.7112 & 1.7576 & 2.6733 & 4.6718 & $6.0646^{\mathrm{a}}$ & 7.2536 & $4.6898^{a}$ & $6.0826^{a}$ & $7.2716^{\mathrm{a}}$ & $5.5787^{\mathrm{a}}$ & $6.9714^{\mathrm{a}}$ & $8.1604^{a}$ \\
\hline \multirow{4}{*}{20} & present & 1.7825 & 1.8289 & 2.7446 & 5.3267 & $7.6643^{\mathrm{a}}$ & $9.6614^{\mathrm{a}}$ & 5.3717 & $7.6823^{a}$ & $9.6794^{\mathrm{a}}$ & 6.2606 & $8.5711^{\mathrm{a}}$ & $10.5682^{a}$ \\
\hline & СРT & 1.8076 & 1.8540 & 2.7698 & 5.5814 & 8.4069 & 10.8715 & 5.6264 & $8.4249^{a}$ & $10.8895^{\mathrm{a}}$ & 6.5153 & $9.3138^{\mathrm{a}}$ & $11.7783^{a}$ \\
\hline & FSDT & 1.7825 & 1.8286 & 2.7380 & 5.3100 & 7.5546 & 9.3049 & 5.3542 & $7.5716^{\mathrm{a}}$ & $9.3217^{\mathrm{a}}$ & 6.2277 & $8.4083^{a}$ & $10.1518^{a}$ \\
\hline & HSDT & 1.7825 & 1.8289 & 2.7446 & 5.3267 & $7.6643^{a}$ & $9.6614^{\mathrm{a}}$ & 5.3717 & $7.6823^{a}$ & $9.6794^{\mathrm{a}}$ & 6.2606 & $8.5711^{\mathrm{a}}$ & $10.5682^{a}$ \\
\hline \multirow{4}{*}{50} & present & 1.8036 & 1.8500 & 2.7657 & 5.5390 & $8.2784^{\mathrm{a}}$ & $10.6576^{\mathrm{a}}$ & 5.5840 & $8.2964^{\mathrm{a}}$ & $10.6756^{\mathrm{a}}$ & 6.4729 & $9.1853^{\mathrm{a}}$ & $11.5645^{\mathrm{a}}$ \\
\hline & CPT & 1.8076 & 1.8540 & 2.7698 & 5.5814 & 8.4069 & 10.8715 & 5.6264 & $8.4249^{a}$ & $10.8895^{\mathrm{a}}$ & 6.5153 & $9.3138^{\mathrm{a}}$ & $11.7783^{a}$ \\
\hline & FSDT & 1.8036 & 1.8499 & 2.7653 & 5.5361 & 8.2566 & 10.5810 & 5.5810 & $8.2744^{a}$ & $10.5989^{a}$ & 6.4689 & $9.1597 \mathrm{a}$ & $11.4835^{a}$ \\
\hline & HSDT & 1.8036 & 1.8500 & 2.7657 & 5.5390 & $8.2784^{a}$ & $10.6576^{a}$ & 5.5840 & $8.2964^{a}$ & $10.6756^{\mathrm{a}}$ & 6.4729 & $9.1853^{\mathrm{a}}$ & $11.5645^{\mathrm{a}}$ \\
\hline \multirow{4}{*}{100} & present & 1.8066 & 1.8530 & 2.7687 & 5.5707 & $8.3744^{\mathrm{a}}$ & $10.8172^{\mathrm{a}}$ & \multirow{4}{*}{$\begin{array}{l}5.6158 \\
5.6264 \\
5.6150 \\
5.6158\end{array}$} & \multirow{4}{*}{$\begin{array}{l}8.3924^{a} \\
8.4249^{a} \\
8.3867^{a} \\
8.3924^{a}\end{array}$} & \multirow{4}{*}{$\begin{array}{l}10.8352^{\mathrm{a}} \\
10.8895^{\mathrm{a}} \\
10.8151^{\mathrm{a}} \\
10.8352^{\mathrm{a}}\end{array}$} & 6.5046 & $9.2813^{\mathrm{a}}$ & $11.7241^{\mathrm{a}}$ \\
\hline & СРТ & 1.8076 & 1.8540 & 2.7698 & 5.5814 & 8.4069 & 10.8715 & & & & 6.5153 & $9.3138^{\mathrm{a}}$ & $11.7783^{\mathrm{a}}$ \\
\hline & FSDT & 1.8066 & 1.8530 & 2.7687 & 5.5700 & 8.3687 & 10.7972 & & & & 6.5038 & $9.2752^{\mathrm{a}}$ & $11.7035^{\mathrm{a}}$ \\
\hline & HSDT & 1.8066 & 1.8530 & 2.7687 & 5.5707 & $8.3744^{\mathrm{a}}$ & $10.8172^{\mathrm{a}}$ & & & & 6.5046 & $9.2813^{\mathrm{a}}$ & $11.7241^{\mathrm{a}}$ \\
\hline
\end{tabular}

${ }^{a}$ Mode for plate is $(m, n)=(1,2)$.

Table 3: Comparison of nondimensional critical buckling load of square plates subjected to biaxial compressive load

Figures 4 show the effect of the side-to-thickness ratio $(a / b)$ on the dimensionless critical buckling $\bar{N}$ when the square plate $(a / b=1)$ without elastic foundation or resting on Winkler's or Pasternak's elastic foundations using the present refined shear deformation theory. It is noted that $\bar{N}$ increases rapidly with increasing side-to-thickness ratio. However, for the plate without elastic foundation or resting on one parameter Winkler's foundation, the variation of the dimensionless critical buckling $\bar{N}$ is almost independent of the side-to-thickness ratio $(a / b)$ when this latter is higher than 25 . It can be also seen that the presence of elastic foundations lead to an increase of the dimensionless critical buckling $\bar{N}$.

Figures 5 and 6 show the variation of the critical load of the dimensionless buckling $\bar{N}$ of the rectangular composite plates without elastic foundation or resting on Winkler's or Pasternak's elastic foundations as a function of the modulus ratio $\left(E_{1} / E_{2}\right)$.The plate is assumed to be subjected to axial loading shown in Fig. 3 (uniaxial compression and biaxial compression). It is found that the critical load of dimensionless buckling increases monotonically as the the modulus ratio $\left(E_{1} / E_{2}\right)$ increases. It is also noted that the critical dimensionless load $\bar{N}$ of the rectangular composite plates under unaxial compression is greater than that of a plate under biaxial compression. 

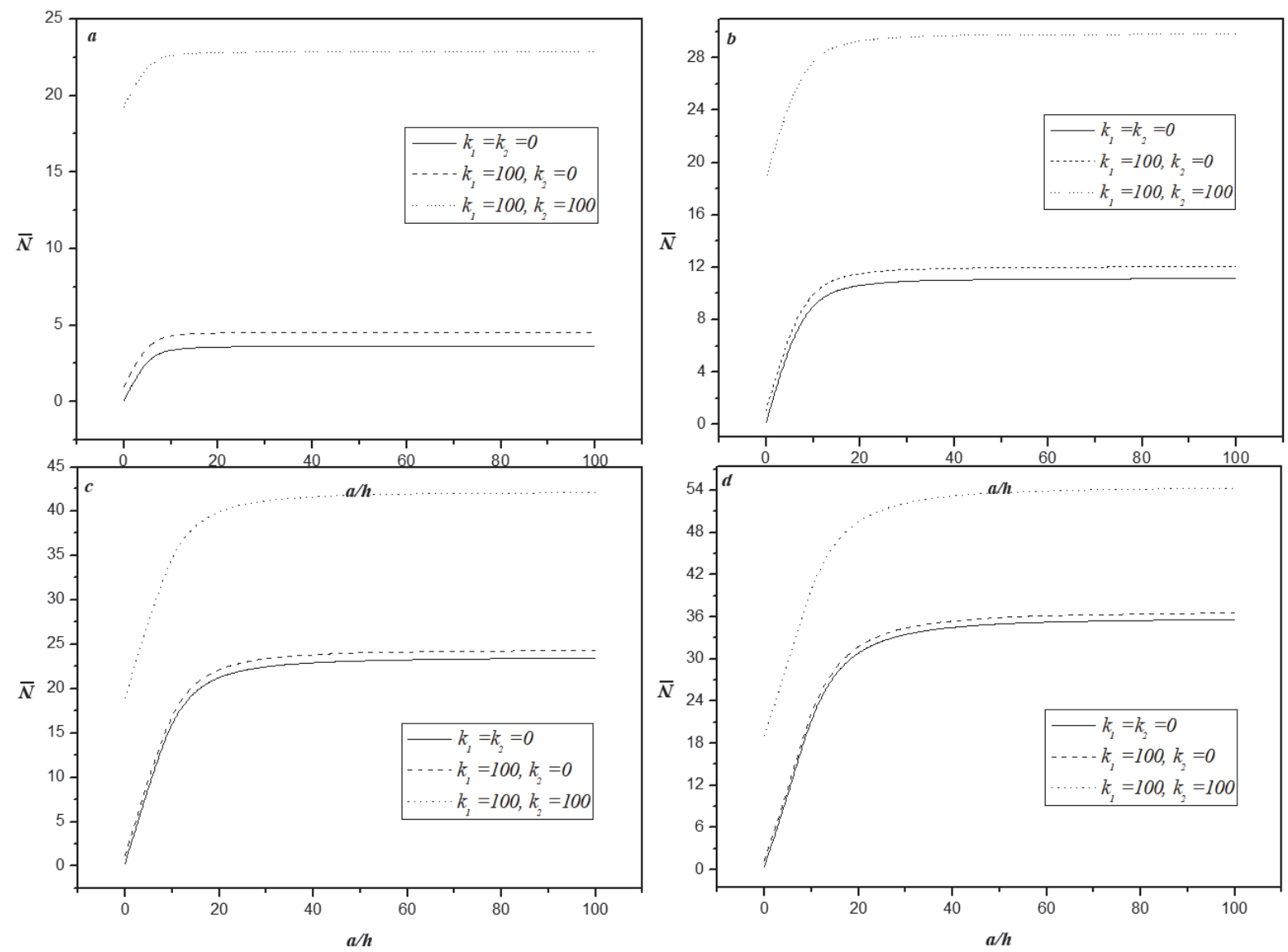

Figure 4: The effect of side-to-thickness and modulus ratios on the critical buckling load of square plate with or without elastic foundations subjected to uniaxial compression: (a)isotropic,(b)E1/E2 =10, (c)E1/E2 =25 and (d)E1/E2= 40 .
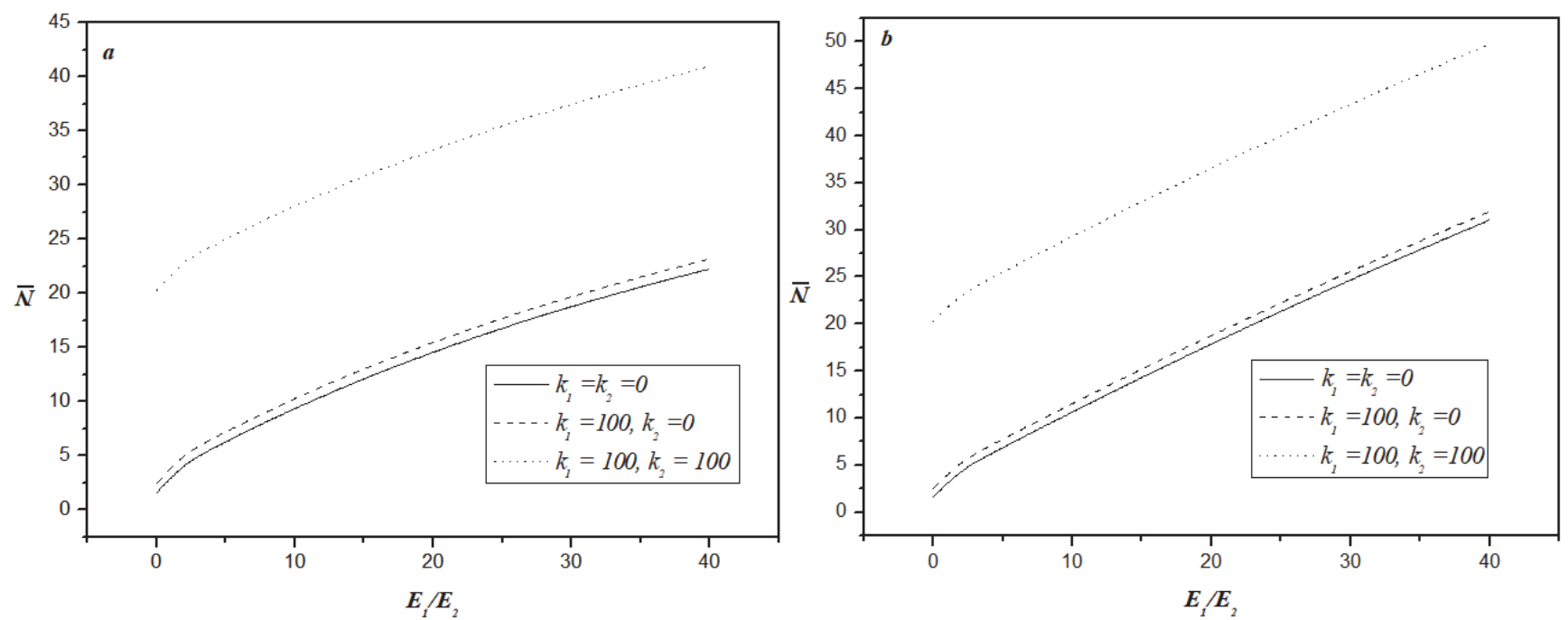

Figure 5: The effect of modulus ratio on the critical buckling load of square plate with or without elastic foundations subjected to uniaxial compression : $(\mathrm{a}) \mathrm{a}=10 \mathrm{~h}$ and $(\mathrm{b}) \mathrm{a}=20 \mathrm{~h}$. 

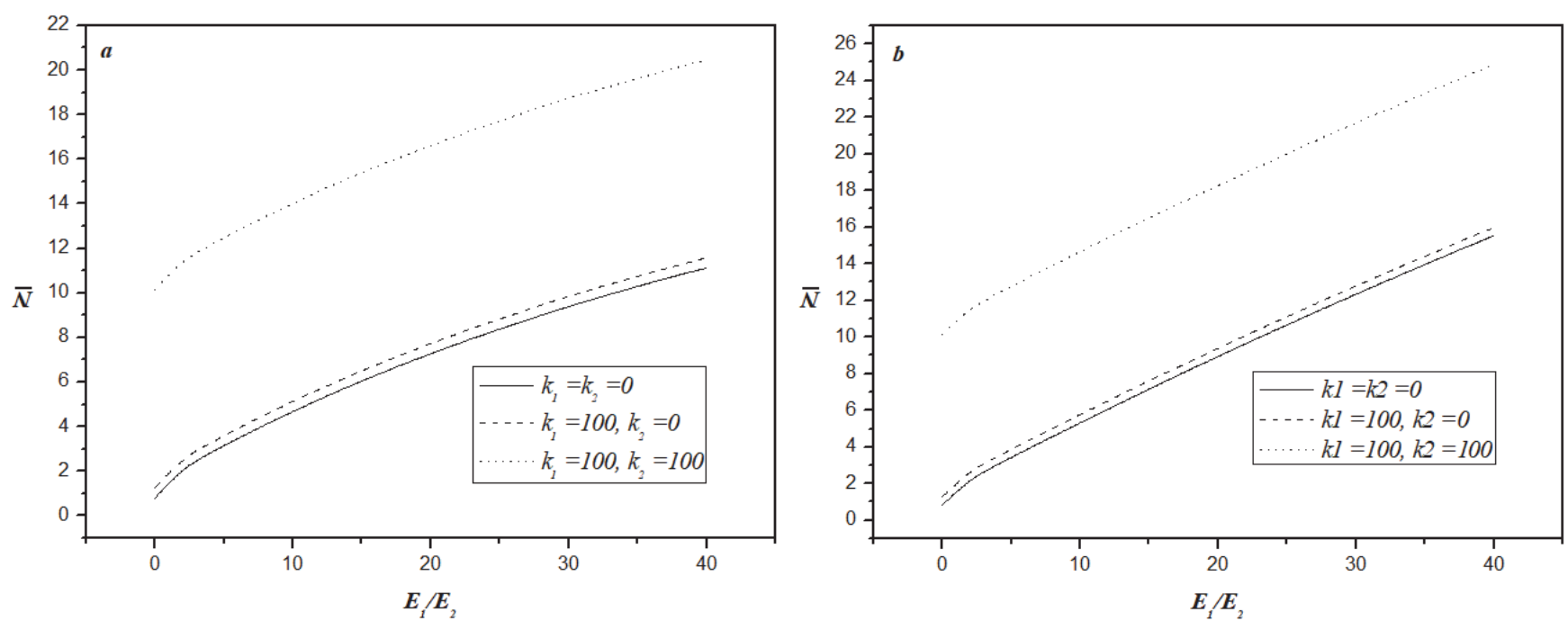

Figure 6: The effect of modulus ratio on the critical buckling load of square plate with or without elastic foundations subjected to biaxial compression: $(\mathrm{a}) \mathrm{a}=10 \mathrm{~h}$ and $(\mathrm{b}) \mathrm{a}=20 \mathrm{~h}$.

\section{CONCLUSION}

A refined and simple shear deformation theory is presented for mechanical buckling of rectangular composite plates in contact with two-parameter elastic foundation. Unlike the conventional shear deformation theories, the proposed refined shear deformation theory contains only four unknowns and has strong similarities with the CPT in many aspects, accounts for a quadratic variation of the transverse shear strains across the thickness, and satisfies the zero traction boundary conditions on the top and bottom surfaces of the plate without using shear correction factors. To clarify the effect of shear deformation on the critical buckling, the results obtained by the present theory as well as HSDT, S and FSDT are compared with those obtained by CPT. It is shown through the numerical examples that the results of the shear deformation plate theories are lower than those of the CPT, indicating the shear deformation effect. All comparison studies show that the critical buckling mechanical obtained by the proposed theory with four unknowns are almost identical with those predicted by other shear deformation theories containing five unknowns. It can be concluded that the proposed theory is accurate and efficient in predicting the mechanical buckling responses of rectangular composite plates resting on two parameter (Pasternak's model) elastic foundations. Due to the interesting features of the present theory, the present findings will be a useful benchmark for evaluating the reliable of other future plate theories.

\section{REFERENCES}

[1] Seyvet, J. (2002). The French composite materials industry (Louis Berreur, Bertrand de Maillard \& Stanislas Nösperger., Paris).

[2] Gay, D. (2014). Design and Applications (Composite Materials third edition, CRC Press) .

[3] Ponte Castañeda, P and Suquet, P. (1997). Nonlinear composites, Adv. Appl. Mech., 34, pp. 171-302.

[4] Milton, G. W. (2002). The Theory of Composites Cambridge University Press.

[5] Moulinec, H. and Suquet, P. (1998). A numerical method for computing the overall response of nonlinear composites with complex microstructure, Comput. Meth-ods Appl. Mech. Eng. 157, pp. 69-94.

[6] Jones, R. M. (1998). Mechanics of Composite Materials, CRC Press.

[7] Timoshenko, S.P., Woinowsky-Krieger S. (1959), Theory of plates and shells, New York: McGraw-Hill.

[8] Timoshenko, S. P., Gere, J. M. (1961). Theory of elastic stability, New York, McGraw-Hill.

[9] Bank, L., Yin, J. (1996). Buckling of orthotropic plates with free and rotationally restrained unloaded edges, Thin Wall Struct. 24(1), pp. 83-96.

[10] Kang, J. H., Leissa, A. W. (2005). Exact solutions for the buckling of rectangular plates having linearly varying in-plane loading on two opposite simply supported edges, Int J Solids Struct, 42(14), pp. 4220-38. 
[11] Aydogdu, M., Ece, M. C. (2006). Buckling and vibration of non-ideal simply supported rectangular isotropic plates, Mech Res Commun, 33(4), pp. 532-540.

[12] Hwang, I., Lee, J. S. (2006). Buckling of orthotropic plates under various inplane loads, KSCE J Civ Eng, 10(5), pp. 349-356.

[13] Reissner, E. (1945). The effect of transverse shear deformation on the bending of elastic plates, J Appl Mech-T ASME, 12(2), pp. 69-77.

[14] Mindlin, R. D. (1951). Influence of rotary inertia and shear on flexural motions of isotropic, elastic plates,“. J Appl Mech-T ASME, 18(1), pp. 31-38.

[15] Levinson, M. (1980). An accurate simple theory of the statics and dynamics of elastic plates, Mech Res Commun, 7(6), pp. 343-350.

[16] Reddy, J. N. (1984). A simple higher-order theory for laminated composite plates, J. Appl. Mech. 51, pp. 745-752.

[17] Shimpi, R. P., Patel, H. G. (2006). A two variable refined plate theory for orthotropic plate analysis, Int J Solids Struct 43(22-23), pp. 6783-6799.

[18] Khalfi, Y., Houari, M.S.A. and Tounsi, A. (2014). A refined and simple shear deformation theory for thermal buckling of solar functionally graded plates on elastic foundation, Int. J. Comput. Method 11(5), 1350077.

[19] Abdelaziz, H. H., Atmane, H. A. Mechab, I., Boumia, L., Tounsi, A. and Adda Bedia, E. A. (2011). Static analysis of functionally graded sandwich plates using an efficient and simple refined theory, Chinese J. Aeronaut 24, pp. 434-448.

[20] Aiello, M. A. and Ombres, L. (1999). Buckling and vibrations of unsymmetric laminates resting on elastic foundations under in-plane and shear forces, Compos. Struct. 44, pp. 31-41.

[21] Draiche, K., Tounsi, A. and Khalfi, Y. (2014), A trigonometric four variable plate theory for free vibration of rectangular composite plates with patch mass, Steel Compos. Struct., Int. J 17(1), pp. 69-81.

[22] Seung-Eock, K., Huu-Tai, T., Jaehong, L. (2009). Buckling analysis of plates using the two variable refined plate theory, Thin-Walled Structures 47, pp. 455-462

[23] Whitney, J. M. and Pagano, N. J. (1970). Shear deformation in heterogeneous anisotropicplates, J. Appl. Mech. 37, pp. 1031-1036.

[24] Reddy, J. N. (1984). A refined nonlinear theory of plates with transverse shear deformation, Int J Solids Struct 20(9), pp. 881-896.

[25] Reddy, J. N. (1997). Mechanics of laminated composite plate: theory and analysis, New York, CRC Press. 